Keywords: epidemiology; breast cancer radiotherapy; radiation-related heart disease; radiation-related lung cancer; long-term effects; mortality

\title{
Radiation-related mortality from heart disease and lung cancer more than 20 years after radiotherapy for breast cancer
}

\author{
K E Henson ${ }^{*}, 1$, P McGale $^{1}$, C Taylor ${ }^{1}$ and S C Darby ${ }^{1}$ \\ ${ }^{1}$ Clinical Trial Service Unit (CTSU), University of Oxford, Richard Doll Building, Old Road Campus, Roosevelt Drive, Oxford OX3 \\ $7 L F, U K$
}

Background: Radiation-related heart disease and lung cancer can occur following radiotherapy for breast cancer but the duration of any mortality risk is uncertain.

Methods: Mortality ratios, by laterality of breast cancer, were estimated using Poisson regression for 558871 women recorded with breast cancer during 1973-2008 in the Surveillance, Epidemiology and End Results (SEER) cancer registries and followed until 01 January 2009.

Results: For women diagnosed with breast cancer during 1973-1982 and given radiotherapy shortly afterwards, the cardiac mortality ratios, left-sided vs right-sided, were 1.19 (1.03-1.38), 1.35 (1.05-1.73), 1.64 (1.26-2.14) and 1.90 (1.52-2.37) at <10, 10-14, $15-19$ and $20+$ years since diagnosis $(2 p$ for trend: $<0.001)$. The lung cancer mortality ratios, ipsilateral vs contralateral, in these women were 1.05 (0.57-1.94), 2.04 (1.28-3.23) and 3.87 (2.19-6.82) at <10, 10-19 and $20+$ years, respectively, (2p for trend: 0.002$)$. For women irradiated during 1983-92 there was evidence of radiation-related mortality for lung cancer, but not for heart disease. For women irradiated since 1993 there is, as yet, little evidence of any radiation-related mortality.

Conclusion: In this population, the radiation-related risks were larger in the third decade after exposure than during the first two decades.

In early breast cancer, radiotherapy can reduce the risk of death from breast cancer itself (Early Breast Cancer Trialists' Collaborative Group (2011)). However, the treatment usually involves some incidental irradiation of the heart and lungs which may increase the subsequent risks of heart disease and lung cancer. Mortality among women registered with breast cancer in the Surveillance, Epidemiology and End Results (SEER) cancer registries during 1973-2001 has previously been reported, giving insight into radiation-related mortality during the first two decades after exposure (Darby et al, 2005). We now present mortality up to 01 January 2009 providing, for the first time, information on the risks of death from radiation-related heart disease and lung cancer in this population during the third decade after exposure.

\section{MATERIALS AND METHODS}

Information on cause-specific mortality in women registered with invasive breast cancer (localised or regional) during 19732008 was obtained from the SEER public-use data set (Surveillance, Epidemiology and End Results (SEER) Program (www.seer. cancer.gov) Research Data (1973-2008), National Cancer Institute, DCCPS, Surveillance Research Program, Cancer Statistics Branch (released January 2011)). Women aged 20-79 years at breast cancer diagnosis were included unless they had previously been registered with a different cancer, their cancer was bilateral, of unknown laterality, metastatic, diagnosed at autopsy, or ascertained only from the death certificate. All deaths certified as

*Correspondence: K E Henson; E-mail: katherine.henson@ctsu.ox.ac.uk

Received 17 August 2012; revised 13 November 2012; accepted 20 November 2012; published online 20 December 2012 
due to heart disease (ICD-10 I00-09, I11, I13, I20-51) were included in the analysis. Deaths from metastatic breast cancer can sometimes be registered as lung cancer. Therefore, deaths certified as due to lung cancer (ICD-10 C34) were included only if microscopically confirmed lung cancer was recorded in the SEER data set.

Women with breast cancer who are selected for radiotherapy may have different mortality rates from those who are not selected for reasons unrelated to radiotherapy (McGale and Darby, 2008). Comparisons that avoid these selection effects can, however, be performed, as the radiation dose to the heart is generally greater in left-sided than in right-sided breast cancer (Taylor et al, 2007). Therefore, a comparison of cardiac mortality in irradiated women with left-sided cancer $v s$ irradiated women with right-sided cancer can give a valid indication of the extent of any radiation-related mortality (Vandenbroucke, 2004). Similarly, the radiation dose to the ipsilateral lung from breast cancer radiotherapy is generally greater than to the contralateral lung. Thus a comparison of mortality from ipsilateral lung cancer compared with contralateral lung cancer among irradiated women can be used to assess the presence of any radiation-related increase in lung cancer mortality.

Each woman's contribution to the person-years at risk ran from the date of breast cancer diagnosis to the earliest of 1st January 2009, death, loss to follow-up, or 85th birthday. Mortality ratios were estimated using Poisson regression with stratification by calendar year of diagnosis, time since diagnosis, age (all in 5-year groups), and race (white, black, other/unknown). Over-dispersion tests were performed, but no adjustments were needed. Tests for trend were performed using variance-weighted least squares assuming Poisson variation. Significance tests were two-sided. Calculations used Stata version 12.

\section{RESULTS}

A total of 558871 women were included in the analysis. Similar proportions of women with left-sided and right-sided breast cancer were recorded as receiving radiotherapy (left-sided: 45.8\% (130 285 women), right-sided: 46.2\% (126691 women) (Table 1)). For women not recorded as receiving radiotherapy, there was little evidence that mortality from heart disease differed in women with left-sided and right-sided cancer (cardiac mortality ratio, left-sided vs right-sided: 1.02 , 95\% confidence interval (CI) 0.99-1.06, $2 p=0.16$ ). However, for women recorded as receiving radiotherapy, there was an excess of cardiac deaths following left-sided cancer (cardiac mortality ratio, left-sided vs right-sided: 1.08, 95\% CI $1.03-1.14,2 p=0.002$ ).

Considering only women recorded as receiving radiotherapy during 1973-1982, the cardiac mortality ratio, left-sided $v$ s rightsided, was raised during the first decade after cancer diagnosis (1.19, 95\% CI 1.03-1.38) and subsequently increased further, taking values 1.35 (1.05-1.73), 1.64 (1.26-2.14), and 1.90 (1.522.37 ), respectively, in periods $10-14,15-19$ and $20+$ years since breast cancer diagnosis ( $2 p$ for trend $<0.001$, see Figure 1). For women receiving radiotherapy after 1982, there was little evidence of any radiation-related increase in heart disease mortality either during the first decade after breast cancer diagnosis or later, although follow-up is, as yet, incomplete.

For women not recorded as receiving radiotherapy, the lung cancer mortality ratio, ipsilateral $v s$ contralateral, was 0.97 (95\% CI $0.89-1.06,2 p=0.50)$, while for irradiated women it was $1.30(95 \%$ CI 1.16-1.45, $2 p<0.001)$. For women diagnosed with breast cancer during 1973-1982 and irradiated, the lung cancer mortality ratio, ipsilateral $v s$ contralateral, increased with time since breast cancer diagnosis, taking values 1.05 (95\% CI 0.57-1.94), 2.04 (1.28-3.23), and 3.87 (2.19-6.82) in the first, second, and third decades since breast cancer diagnosis ( $2 p$ for trend $=0.002$, see Figure 2). For women diagnosed during 1983-92 and irradiated, the lung cancer mortality ratio, ipsilateral vs contralateral, also showed a substantial increase more than 20 years after exposure $(3.87, \mathrm{CI}$ 1.24-11.31, data not shown).

\section{DISCUSSION}

Several studies of mortality from radiation-related heart disease and lung cancer have suggested that where there is a risk, it may continue for many years after exposure (Inskip et al, 1994; Preston et al, 2003; Early Breast Cancer Trialists' Collaborative Group 2005; Prochazka et al, 2005; Bouillon et al, 2011). However, no study has demonstrated so clearly a progressive increase in risk with time since exposure lasting into the third decade. In this population, the radiation-related increases in mortality are very clear for women irradiated during 1973-82. For women irradiated

Table 1. Summary of data by laterality, radiotherapy status and calendar year of diagnosis

\begin{tabular}{|c|c|c|c|c|}
\hline Calendar year of diagnosis & $\begin{array}{l}\text { Women } \\
\text { Left/right }\end{array}$ & $\begin{array}{l}\text { Person-years } \\
\text { Left / right }\end{array}$ & $\begin{array}{l}\text { Heart disease deaths } \\
\text { Left/right }\end{array}$ & $\begin{array}{l}\text { Lung cancer deaths } \\
\text { Ipsilateral / contralateral }\end{array}$ \\
\hline \multicolumn{5}{|c|}{ Radiotherapy recorded } \\
\hline $\begin{array}{l}\text { 1973-82 } \\
1983-92 \\
1993-02 \\
\text { 2003-08 } \\
\text { Total: radiotherapy recorded } \\
\text { Mortality ratio }\end{array}$ & $\begin{array}{c}7109 / 6615 \\
14582 / 13945 \\
56094 / 54369 \\
52500 / 51762 \\
130285 / 126691 \\
-\end{array}$ & $\begin{array}{c}86198 / 81516 \\
195017 / 187240 \\
475475 / 461071 \\
151899 / 150327 \\
908589 / 880154 \\
-\end{array}$ & $\begin{array}{c}926 / 624 \\
844 / 783 \\
1160 / 1155 \\
187 / 181 \\
3117 / 2743 \\
1.08(1.03-1.14)^{a}\end{array}$ & $\begin{array}{c}134 / 62 \\
208 / 155 \\
317 / 284 \\
50 / 44 \\
709 / 545 \\
1.30(1.16-1.45)^{\mathrm{b}}\end{array}$ \\
\hline \multicolumn{5}{|c|}{ Radiotherapy not recorded } \\
\hline $\begin{array}{l}\text { 1973-82 } \\
1983-92 \\
1993-02 \\
2003-08 \\
\text { Total: radiotherapy not recorded } \\
\text { Mortality ratio }\end{array}$ & $\begin{array}{c}25748 / 24101 \\
35314 / 33717 \\
51190 / 49130 \\
42244 / 40451 \\
154496 / 147399 \\
-\end{array}$ & $\begin{array}{c}375772 / 355024 \\
445396 / 429779 \\
420979 / 404480 \\
114935 / 110326 \\
1357082 / 1299609 \\
-\end{array}$ & $\begin{array}{c}2589 / 2426 \\
2651 / 2361 \\
1886 / 1808 \\
329 / 302 \\
7455 / 6897 \\
1.02(0.99-1.06)^{a}\end{array}$ & $\begin{array}{c}289 / 266 \\
342 / 363 \\
268 / 306 \\
38 / 50 \\
397 / 985 \\
0.97(0.89-1.06)^{b}\end{array}$ \\
\hline
\end{tabular}




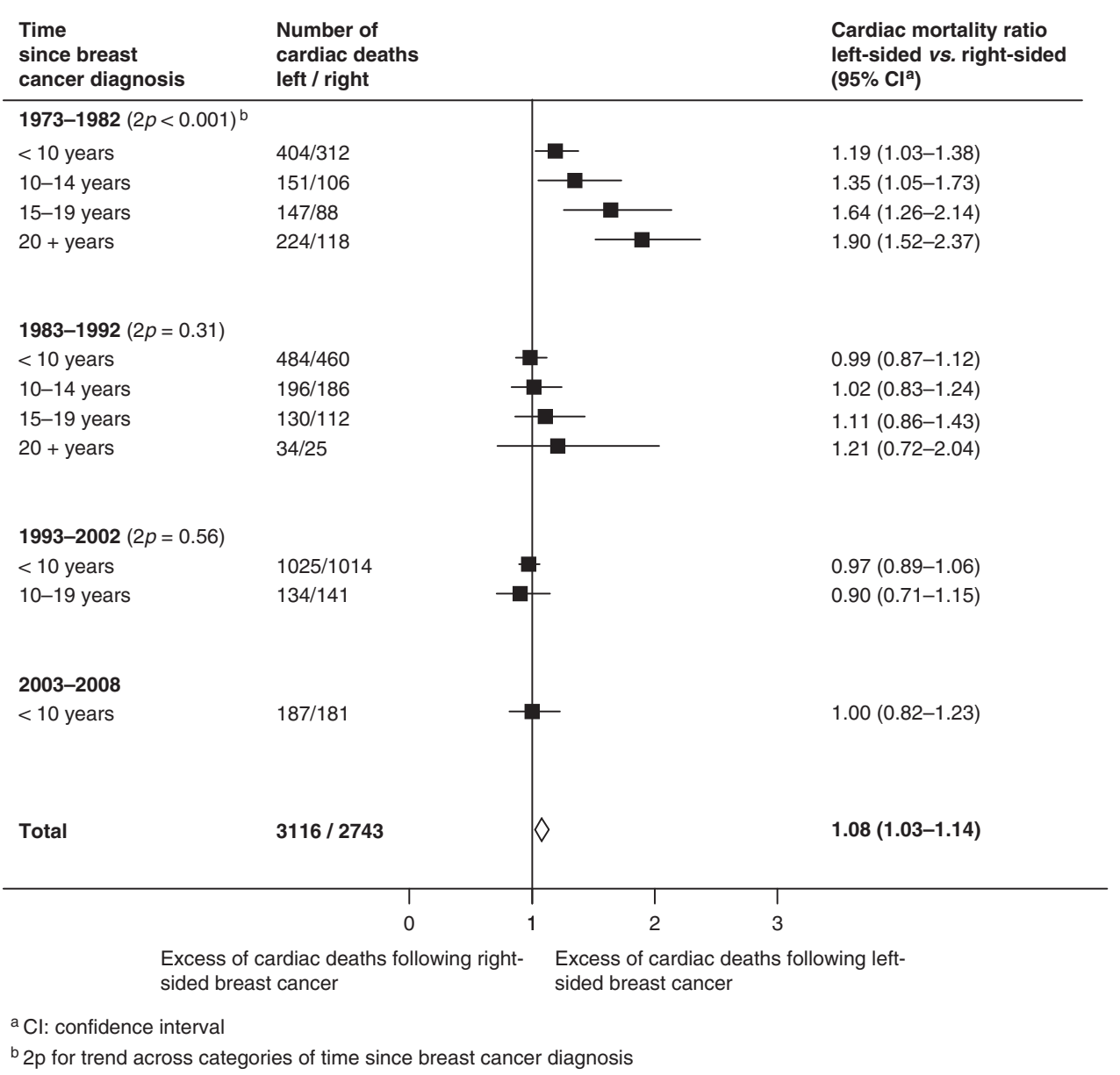

Figure 1. Cardiac mortality ratios, left-sided vs right-sided breast cancer, for women treated with radiotherapy by calendar period of breast cancer diagnosis and time (in years) since breast cancer diagnosis.

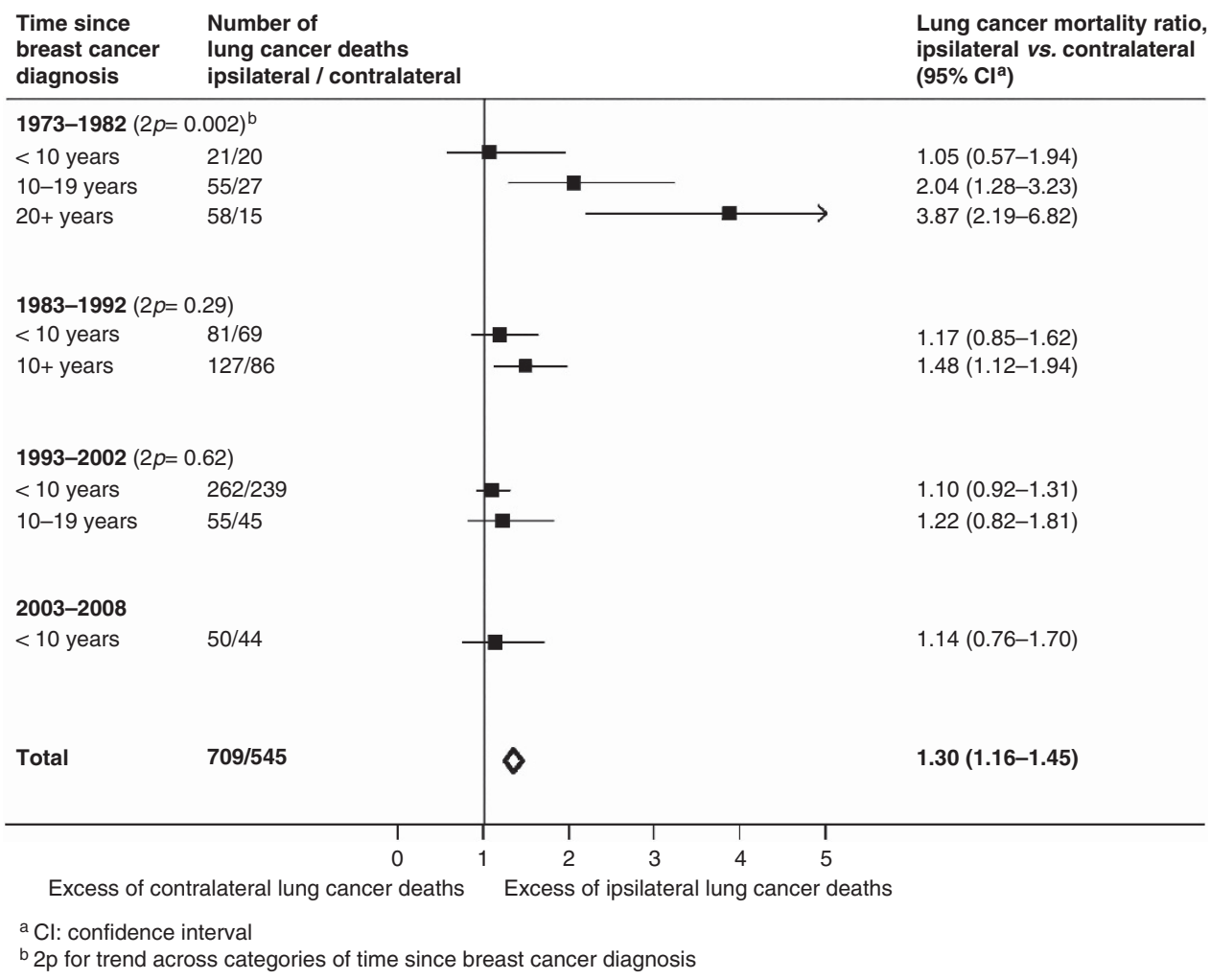

Figure 2. Lung cancer mortality ratios, ipsilateral vs contralateral, for women treated with radiotherapy by calendar period of breast cancer diagnosis and time (in years) since breast cancer diagnosis. 
during 1983-92 there is evidence of radiation-related mortality for lung cancer, but not for heart disease. Follow-up of those irradiated since 1993 reveals, as yet, no increase in risk.

Individual radiation doses are not available for the women in this study. Average mean doses to the heart and lungs for women diagnosed with breast cancer in a given decade depend mainly on the prescribed dose, the targets irradiated and the techniques used. There has been little variation in prescribed dose in the United States over the past few decades (Solin et al, 1991; Shank et al, 2000). However, the radiotherapy targets and techniques have changed. One of the main determinants of heart and lung doses has been the use of radiotherapy to the internal mammary nodes. In previous decades, internal mammary irradiation has delivered around 13-17 Gy and 3-10 Gy to the heart for left and right-sided radiotherapy, respectively, and around 13-24 Gy and 3-11 Gy to the ipsilateral and contralateral lungs, respectively, where the tumour dose is $50 \mathrm{~Gy}$ (Prochazka et al, 2005). The use of internal mammary radiotherapy has declined in the United States at least since the 1980s: in a survey of radiation oncology practice, the internal mammary chain was irradiated in $62 \%$ of women after breast conserving surgery in the 1980 s, but in only $1 \%$ of such women in the 1990s. This reduction may explain, at least in part, the reductions in radiation-related cardiac and lung cancer mortality.

The eventual risks for breast cancer patients given radiotherapy today are, as yet, unknown, but will depend on the doses to the heart and lungs. The current average mean heart dose is likely to be around 2-7 Gy for left-sided (Taylor et al, 2008; Jagsi et al, 2010; Schubert et al, 2011) and around $1.5 \mathrm{~Gy}$ for right-sided breast cancer radiotherapy (Taylor et al, 2008). Current average mean lung doses are around 7-18 Gy for the ipsilateral, and around $0.1-3 \mathrm{~Gy}$ for the contralateral lung (Jagsi et al, 2010; Schubert et al, 2011). Therefore, the risks for women irradiated today are likely to be lower.

\section{ACKNOWLEDGEMENTS}

This work was funded by Cancer Research UK.

\section{REFERENCES}

Bouillon K, Haddy N, Delaloge S, Garbay J-R, Garsi J-P, Brindel P, Mousannif A, Le MG, Labbe M, Arriagada R, Jougla E, Chavaudra J, Diallo I, Rubino C, de Vathaire F (2011) Long-term cardiovascular mortality after radiotherapy for breast cancer. J Am Coll Cardiol 57: 445-452.

Darby SC, McGale P, Taylor CW, Peto R (2005) Long-term mortality from heart disease and lung cancer after radiotherapy for early breast cancer: prospective cohort study of about 300000 women in US SEER cancer registries. Lancet Oncol 6: 557-565.

Early Breast Cancer Trialists' Collaborative Group (EBCTCG) (2005) Effects of radiotherapy and of differences in the extent of surgery for early breast cancer on local recurrence and 15-year survival: an overview of the randomised trials. Lancet 366: 2087-2106.

Early Breast Cancer Trialists' Collaborative Group (EBCTCG) (2011) Effect of radiotherapy after breast-conserving surgery on 10-year recurrence and 15-year breast cancer death: meta-analysis of individual patient data for 10801 women in 17 randomised trials. Lancet 378: 1707-1716.

Inskip PD, Stovall M, Flannery JT (1994) Lung cancer risk and radiation dose among women treated for breast cancer. J Natl Cancer Inst 86: 983-988.

Jagsi R, Moran J, Marsh R, Masi K, Griffith KA, Pierce LJ (2010) Evaluation of four techniques using intensity-modulated radiation therapy for comprehensive locoregional irradiation of breast cancer. Int J Radiat Oncol Biol Phys 78: 1594-1603.

McGale P, Darby SC (2008) Commentary: A dose-response relationship for radiation-induced heart disease-current issues and future prospects. Int $J$ Epidemiol 37: 518-523.

Preston DL, Shimizu Y, Pierce DA, Suyama A, Mabuchi K (2003) Studies of mortality of atomic bomb survivors. Report 13: solid cancer and noncancer disease mortality: 1950-1997. Radiat Res 160: 381-407.

Prochazka M, Hall P, Gagliardi G, Granath F, Nilsson BN, Shields PG, Tennis $\mathrm{M}$, Czene K (2005) Ionizing radiation and tobacco use increases the risk of a subsequent lung carcinoma in women with breast cancer: case-only design. J Clin Oncol 23: 7467-7474.

Schubert LK, Gondi V, Sengbusch E, Westerly DC, Soisson ET, Paliwal BR, Mackie TR, Mehta MP, Patel RR, Tomé WA, Cannon GM (2011) Dosimetric comparison of left-sided whole breast irradiation with 3DCRT, forward-planned IMRT, inverse-planned IMRT, helical tomotherapy, and topotherapy. Radiother Oncol 100: 241-246.

Shank B, Moughan J, Owen J, Wilson F, Hanks GE (2000) The 1993-94 patterns of care process survey for breast irradiation after breastconserving surgery - comparison with the 1992 standard for breast conservation treatment. Int J Radiat Oncol Biol Phys 48: 1291-1299.

Solin LJ, Fowble BL, Martz KL, Goodman RL, Hanks GE (1991) Results of the 1983 patterns of care process survey for definitive breast irradiation. Int $J$ Radiat Oncol Biol Phys 20: 105-111.

Taylor CW, Nisbet A, McGale P, Darby SC (2007) Cardiac exposures in breast cancer radiotherapy: 1950s-1990s. Int J Radiat Oncol Biol Phys 69: $1484-$ 1495.

Taylor CW, Povall JM, McGale P, Nisbet A, Dodwell D, Smith JT, Darby SC (2008) Cardiac dose from tangential breast cancer radiotherapy in the year 2006. Int J Radiat Oncol Biol Phys 72: 501-507.

Vandenbroucke JP (2004) When are observational studies as credible as randomised trials? Lancet 363: 1728-1731.

(c) (1) (2) This work is licensed under the Creative Commons Attribution-NonCommercial-Share Alike 3.0 Unported License. To view a copy of this license, visit http://creativecommons. org/licenses/by-nc-sa/3.0/ 